\title{
Bisdemethoxycurcumin exerts pro-apoptotic effects in human pancreatic adenocarcinoma cells through mitochondrial dysfunction and a GRP78-dependent pathway
}

\author{
Haopeng Yang ${ }^{1,2}$, Shengjun Fan ${ }^{1,2}$, Yu An ${ }^{1,2}$, Xin Wang ${ }^{2}$, Yan Pan ${ }^{1,2}$, Yilixiati \\ Xiaokaiti ${ }^{1,2}$, Jianhui Duan ${ }^{1,2}$, Xin Li ${ }^{1,2}$, Lu Tie ${ }^{1,2}$, Min Ye ${ }^{1,3}$, Xuejun Li $^{1,2}$ \\ ${ }^{1}$ State Key Laboratory of Natural and Biomimetic Drugs, Department of Pharmacology, School of Basic Medical Sciences, \\ Peking University, Beijing 100191, China \\ ${ }^{2}$ Beijing Key Laboratory of Tumor Systems Biology, Peking University, Beijing 100191, China \\ ${ }^{3}$ Department of Natural Medicines, School of Pharmaceutical Sciences, Peking University, Beijing 100191, China \\ Correspondence to: Xuejun Li, email: xjli@bjmu.edu.cn \\ Keywords: bisdemethoxycurcumin, gemcitabine, pancreatic cancer, apoptosis, proteomics \\ Received: July 02, $2016 \quad$ Accepted: October 14, $2016 \quad$ Published: November 10, 2016
}

\section{ABSTRACT}

Pancreatic cancer is a highly aggressive malignancy, which is intrinsically resistant to current chemotherapies. Herein, we investigate whether bisdemethoxycurcumin (BDMC), a derivative of curcumin, potentiates gemcitabine in human pancreatic cancer cells. The result suggests that BDMC sensitizes gemcitabine by inducing mitochondrial dysfunctions and apoptosis in PANC-1 and MiaPaCa-2 pancreatic cancer cells. Utilizing two-dimensional gel electrophoresis and mass spectrometry, we identify 13 essential proteins with significantly altered expressions in response to gemcitabine alone or combined with BDMC. Protein-protein interaction network analysis pinpoints glucose-regulated protein 78 (GRP78) as the key hub activated by BDMC. We then reveal that BDMC upregulates GRP78 and facilitates apoptosis through eIF2a/CHOP pathway. Moreover, DJ-1 and prohibitin, two identified markers of chemoresistance, are increased by gemcitabine in PANC-1 cells. This could be meaningfully reversed by BDMC, suggesting that BDMC partially offsets the chemoresistance induced by gemcitabine. In summary, these findings show that BDMC promotes apoptosis through a GRP78-dependent pathway and mitochondrial dysfunctions, and potentiates the antitumor effect of gemcitabine in human pancreatic cancer cells.

\section{INTRODUCTION}

Pancreatic cancer is the fourth leading cause of cancer-related death in United States. The average survival from diagnosis to death is only 4-6 months, and overall 5 -year patient survival rate remains less than $6 \%$ [1]. The poor prognosis in pancreatic cancer is due to the reduced response of patients to chemotherapy and/or radiotherapy. Gemcitabine and erlotinib, the U.S. Food and Drug Administration-approved therapies against pancreatic cancer, produce objective responses in $<10 \%$ of the patients [2]. Though it extends survival by mere 3-6 weeks, gemcitabine (GEM) has been recognized as the first-line single treatment against pancreatic cancer for decades. On top of that, GEM has been proposed in combination regimens to treat non-small cell lung carcinoma (with cisplatin), ovarian cancer (with carboplatin), bladder cancer (with cisplatin) and breast cancer (with paclitaxel) [3]. Though many attempts aimed at sensitizing gemcitabine have been evaluated in recent years, investigations into the specific mechanisms of drug combinations encounter many difficulties including the lack of research strategies and the multi-target traits. Thus, optimized analytical methods are urgently needed to investigate detailed mechanisms and to deliver potent treatments against pancreatic cancer.

Curcumin (diferuloylmethane) is a major constituent of the yellow spice turmeric derived from the rhizomes of Curcuma longa [4]. It has been well documented that curcumin is a safe and nontoxic agent with demonstrable anti-inflammatory, antioxidant, and antitumor properties $[5,6]$. So far, curcumin is one of the most effective agents 
to improve the current antitumor drugs in clinic. However, due to the limited pharmacokinetic profile of curcumin, intensive studies have shifted to the development of curcumin analogues. Accumulating evidence suggests that curcumin analogues with improved potency and antineoplastic activities be the better therapies for certain types of cancers [7]. Among these curcuminoids, BDMC and desmethoxycurcumin (DMC) are more stable in physiological conditions than the lead compound is [8]. To date, BDMC and DMC have not been investigated whether they exhibit antitumor effects to the same extent as curcumin does. Moreover, mechanisms underlying the antitumor properties of these natural products need to be elucidated to develop effective combination regimens against human cancers.

In the present study, proteomics assays combined with computational bioinformatics are adopted to investigate the specific mechanisms by which BDMC efficiently inhibits the viability of chemoresistant pancreatic cancer cells. As reported that PANC-1 cells display the most resistance to gemcitabine [9], twodimensional electrophoresis (2-DE) and mass spectrometry (MS) are performed in PANC-1 cells treated with GEM alone or combined with BDMC to disclose the protein expression profiles. Utilizing protein-protein interaction database, GRP78 is identified as the key hub stimulated by $\mathrm{BDMC}$, and the correlated interaction clusters are herein investigated. Together, the results demonstrate that BDMC causes mitochondrial dysfunction and induces apoptosis in human pancreatic cancer cells at a concentration that is significantly lower than that of curcumin. Also, our study reveals that BDMC promotes apoptosis via a GRP78-dependent pathway and counteracts GEM-induced chemoresistance. Thus, we propose BDMC as a promising treatment for human pancreatic cancer.

\section{RESULTS}

\section{BDMC augments the antitumor effects of GEM in human pancreatic cancer cells}

We first evaluated the $\mathrm{IC}_{50}$ of GEM in PANC-1 and MiaPaCa-2 cells (Figure 1(A), left), and examined the dose-effect curve from $1 \mathrm{nmol} / \mathrm{L}$ to $1 \mu \mathrm{mol} / \mathrm{L}$ in both cell lines (Figure 1(A), right). We determined $25 \mathrm{nmol} / \mathrm{L}$, a dose of no significance, as the concentration of GEM in the following combination treatments. By comparing the effects of curcuminoids on cell viability, we found that BDMC exhibited the highest efficacy in augmenting the inhibitory effects of GEM in MiaPaCa-2 cells (Figure 1(C), left) and PANC-1 cells (Figure 1(C), right). In specific, according to dose-effect curves (Figure 1(B)), BDMC shows significance at $20 \mu \mathrm{mol} / \mathrm{L}$ and reduces the viability by nearly $40 \%$. However, curcumin (CUR) or DMC shows little impact at the same concentration. Regarding combination regimen, we determined
$10 \mu \mathrm{mol} / \mathrm{L}$, a dose of no significance, as the concentration of BDMC in combination treatments. As shown in Figure 1(C), we compared BDMC with CUR, and found that BDMC-GEM is meaningfully more advantageous than CUR-GEM, which simply shows an additive effect of CUR and GEM. However, BDMC-GEM combination reduces $\mathrm{MiaPaCa}-2$ and PANC-1 cell viability by $68 \%$ and $63 \%$ respectively, and noticeably shows a greater efficacy than the aggregate of BDMC and GEM does, suggesting a synergy between BDMC and GEM. These results suggest that BDMC is significantly superior to CUR in reducing the viability of pancreatic cancer cell. Moreover, as shown in Table 1, the addition of BDMC decreased the $\mathrm{IC}_{50}$ of GEM from $6.85 \mu \mathrm{mol} / \mathrm{L}$ to $79.44 \mathrm{nmol} / \mathrm{L}$ in PANC-1 cells and from $0.33 \mu \mathrm{mol} / \mathrm{L}$ to $37.18 \mathrm{nmol} / \mathrm{L}$ in $\mathrm{MiaPaCa}-2$ cells. Together, these data demonstrate that BDMC alone reduces the viability of $\mathrm{MiaPaCa}-2$ and PANC- 1 cell, and improves the efficacy of GEM efficiently in comparisons with curcumin and DMC.

\section{BDMC potentiates GEM in pancreatic cancer cells by inducing apoptosis}

To evaluate whether the decrease in cell viability induced by BDMC was apoptotic, we adopted flow cytometry to detect the presence of cell death, and found apoptosis occurred in more than $60 \%$ of the cells treated with BDMC-GEM combination (Figure 2(A)). We also explored the contents of cleaved-PARP and cleavedcaspase-3 by western blot (Figure 2(B)). Significantly, an increase in the activity of PARP (Figure 2(C), left) and caspase-3 (Figure 2(C), right) was confirmed respectively. Using TUNEL assay and Hoechst staining, cells treated with BDMC-GEM showed early apoptosis (Figure 2(D)). The number of TUNEL-positive cells per HPR was significantly increased in the combination group (Figure 2(E)). These results suggest that BDMC enhances the antitumor effect of GEM by inducing apoptosis.

\section{BDMC induces apoptosis through mitochondrial dysfunctions}

Abnormal oxidative-stress response and the imbalanced levels of intracellular superoxide anions and glutathione (GSH) are both closely associated with CURinduced apoptosis in various types of cancer [10-12]. We investigated the effect of BDMC-GEM on superoxide production and total GSH levels in PANC-1 cells, and observed an increase in the intracellular superoxide production (Figure 3(A)) and a decrease in total GSH (Figure 3(B)). To evaluate mitochondrial function, we utilized fluorescent JC-1 probe, which forms aggregates in intact mitochondria and emits red fluorescence, while forms monomers upon depolarization and emits green fluorescence [13]. BDMC-GEM treatment caused a significant reduction in mitochondrial membrane potential 
(A)
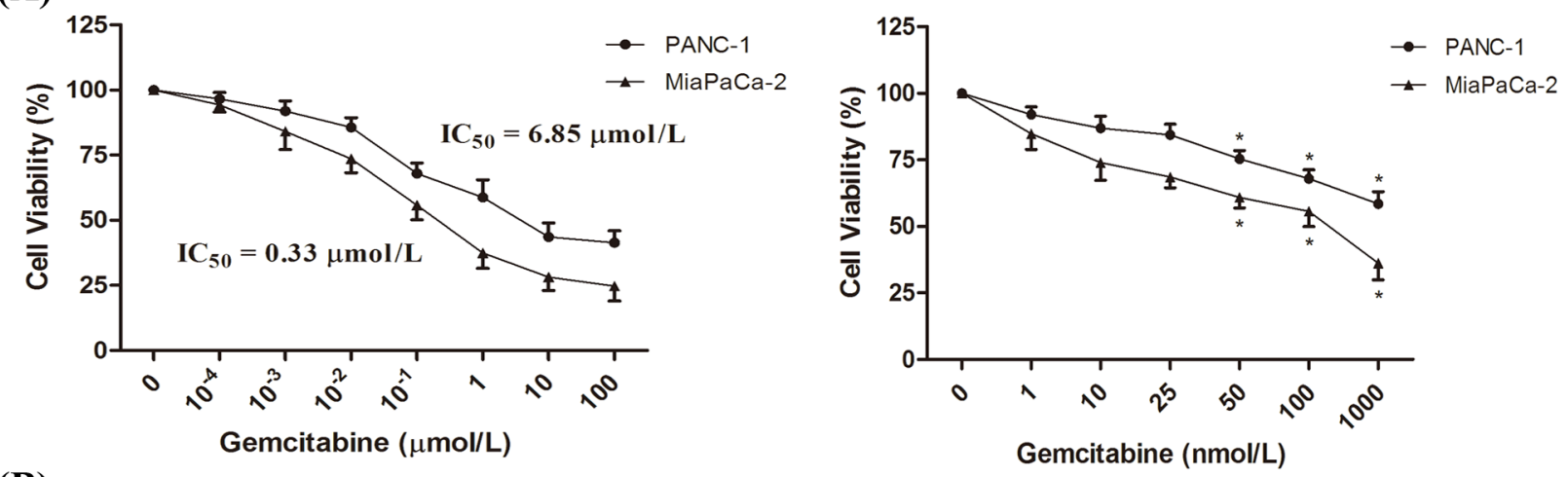

(B)
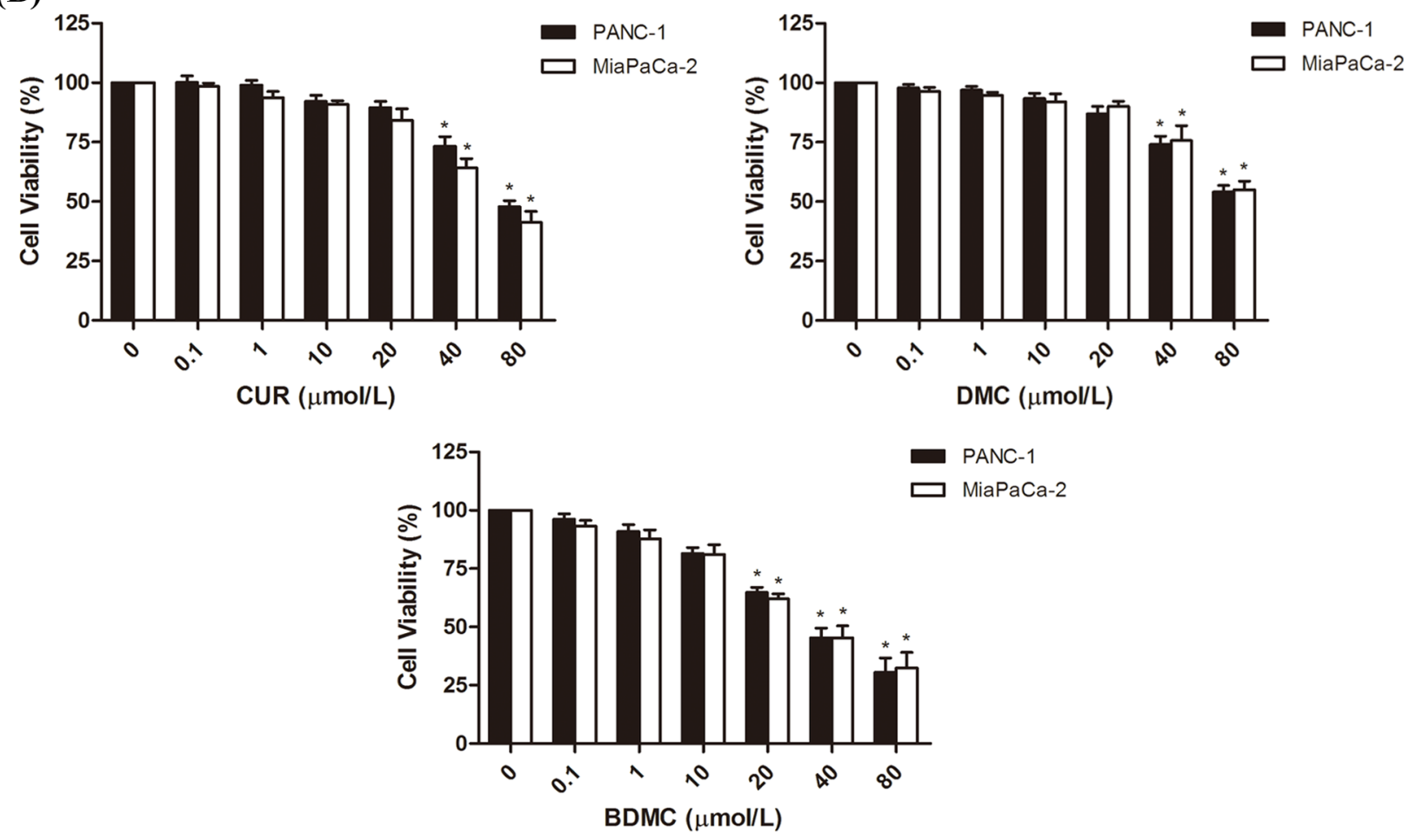

(C)

MiaPaCa-2

PANC-1
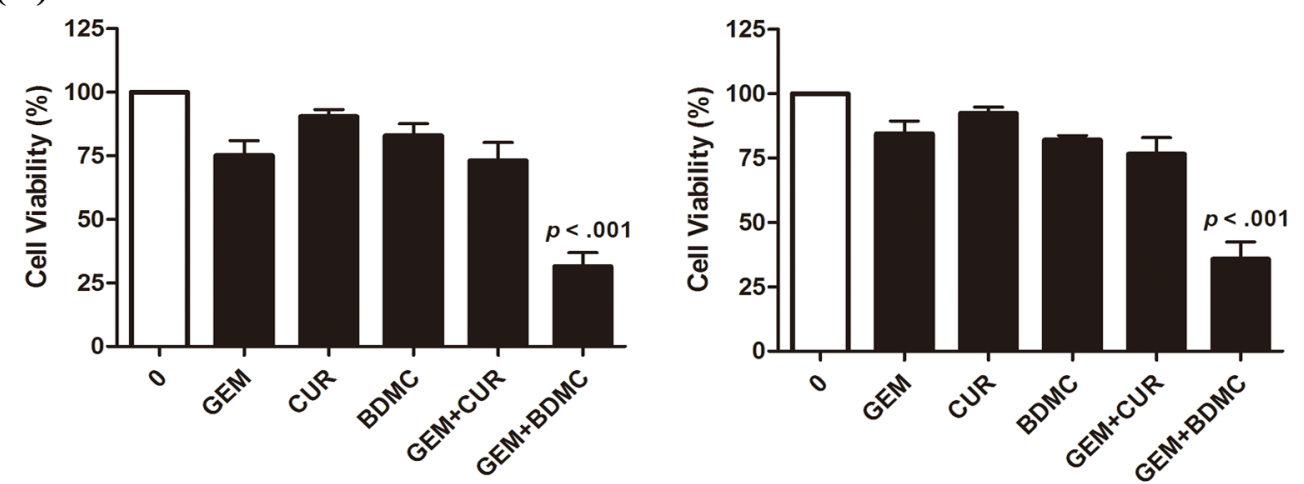

Figure 1: Inhibitory effects of GEM, CUR, DMC, and BDMC in human pancreatic cancer cell. A. cells were treated with GEM of indicated concentrations for $24 \mathrm{~h}$ in 96-well plates. B. cells were treated with CUR, DMC, and BDMC of indicated concentrations for $24 \mathrm{~h}$. Drug efficacy was determined by detecting cell viabilities. C. MiaPaCa-2 and PANC-1 cells were treated with GEM (25nmol/L), BDMC $(10 \mu \mathrm{mol} / \mathrm{L})$, or the combination for $24 \mathrm{~h}$. CUR was used as a comparative drug. Bars are means \pm SD from four independent experiments, $* p<0.01$. 
Table 1: Changed $\mathrm{IC}_{50}$ of gemcitabine in PANC-1 and MiaPaCa-2 cells with BDMC administration

\begin{tabular}{lcc}
\hline Gemcitabine IC $_{\mathbf{5 0}}$ & PANC-1 & MiaPaCa-2 \\
\hline $0 \mu \mathrm{M}$ BDMC & $6.85 \mu \mathrm{M}$ & $0.33 \mu \mathrm{M}$ \\
$10 \mu \mathrm{M}$ BDMC & $79.44 \mathrm{nM}^{* *}$ & $37.18 \mathrm{nM}^{* *}$ \\
\hline
\end{tabular}

** $p<0.01$ (Paired t test, two tailed)

(A)
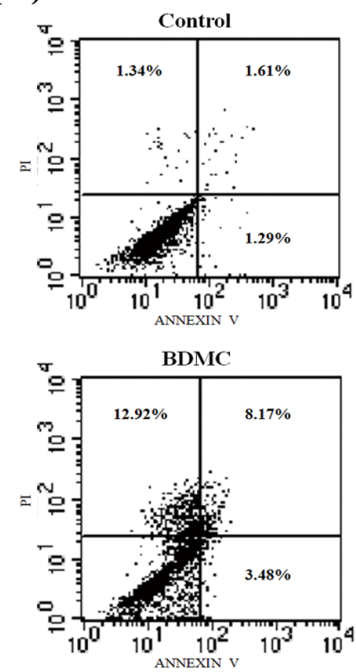

(C)

(D)

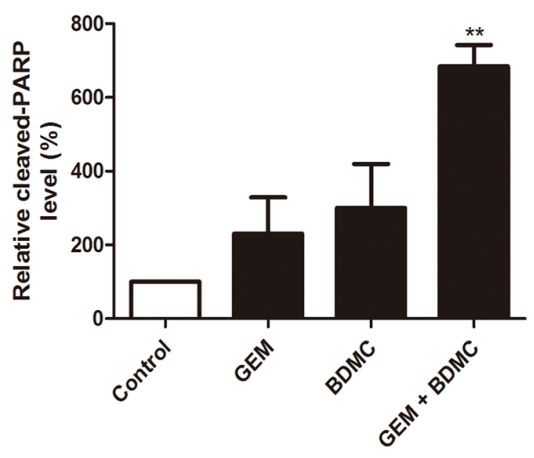

Con
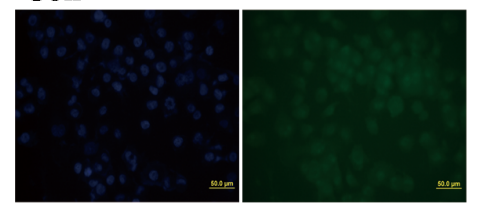

BDMC

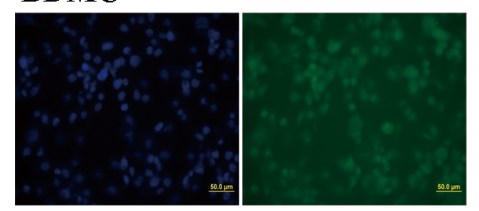

GEM

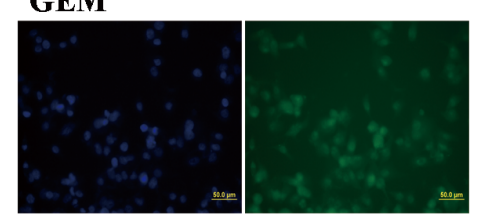

GEM + BDMC

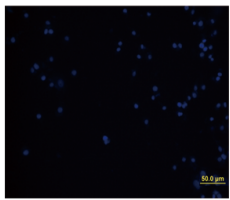

(B)
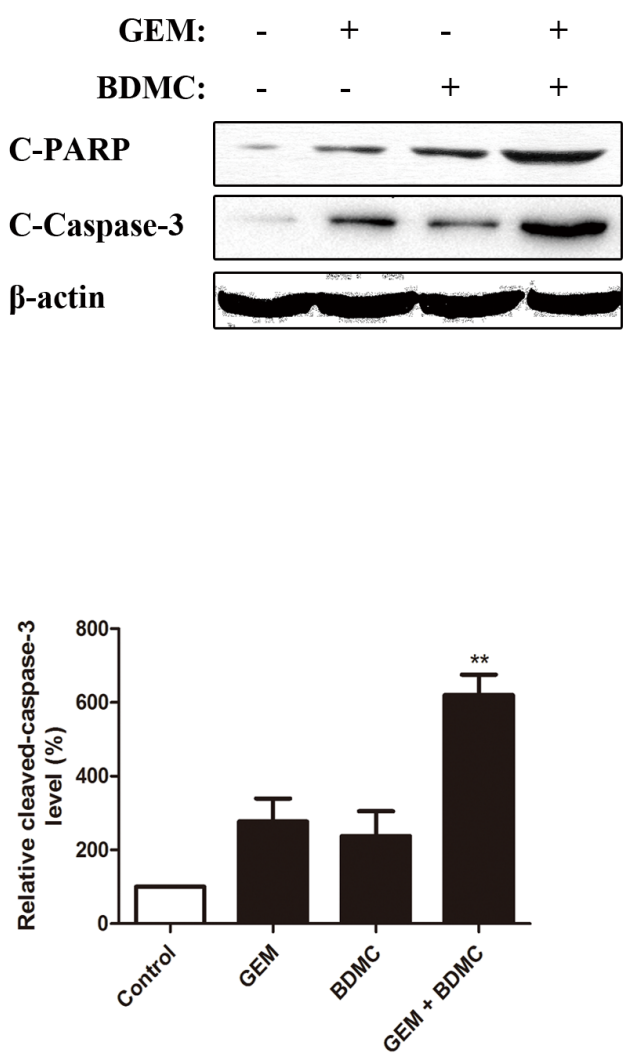

(E)

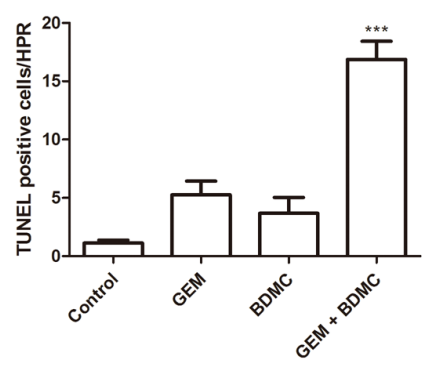

Figure 2: BDMC potentiates GEM in pancreatic cancer cells by inducing apoptosis. A. cells were treated with GEM $(25 \mathrm{nmol} / \mathrm{L}), \mathrm{BDMC}(10 \mu \mathrm{mol} / \mathrm{L})$, or the combination for $24 \mathrm{~h}$. Cells were analyzed for apoptosis by flow cytometry. B. cleaved-PARP and cleaved-Caspase- 3 were detected by western blot. C. densitometric analysis was used for quantification. Values were normalized to $\beta$-actin and were compared with Control levels. Data was shown as means $\pm \mathrm{SD}, \mathrm{n}=3, * * p<0.01$. D. cells treated with indicated drugs were subjected to TUNEL and Hoechst staining reagents. E. the number of TUNEL positive cells per HPR was determined, $* * * p<0.001$. 
$(\Delta \psi)$ in PANC-1 cells (Figure 3(C, D)). Also, a significant increase in the ratio of $\mathrm{Bax}$ to $\mathrm{Bcl}-2$ was detected in cells treated with the combination (Figure 3(E, F)). Curcumin was adopted as a comparative drug, which consistently showed less efficacy in comparison with BDMC. These results demonstrate that BDMC brings about mitochondrial dysfunctions in pancreatic cancer cells.

\section{NAC partially reverses BDMC-induced apoptosis in human pancreatic cancer cells}

Antioxidant N-Acetyl Cysteine (NAC) was utilized to rescue BDMC-induced apoptosis. Flow cytometry results showed that the pre-incubation of $200 \mu \mathrm{M}$ NAC for $1 \mathrm{~h}$ could partially reverse the apoptotic events by $25 \%$
(A)

(C)

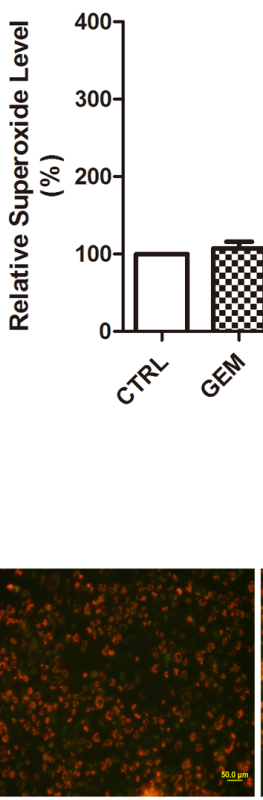

Con

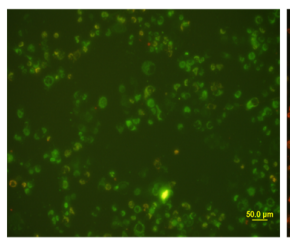

GEM + BDMC

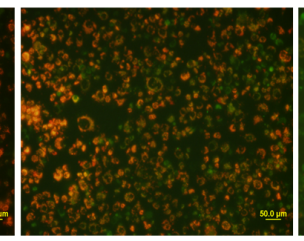

GEM

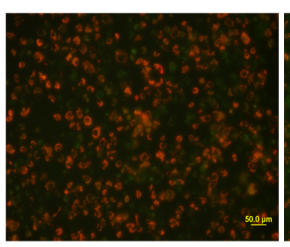

NAC
(B)

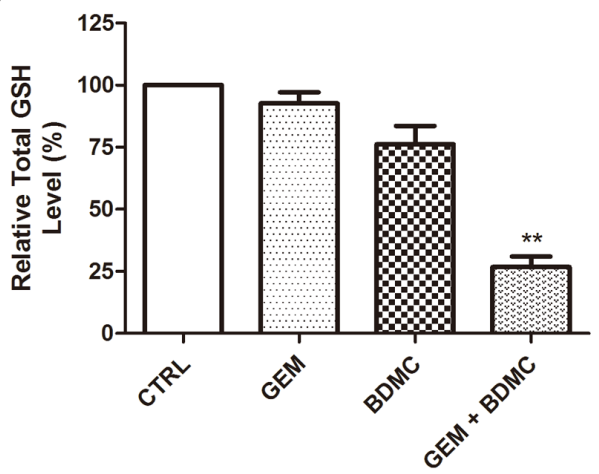

(D)
(E)

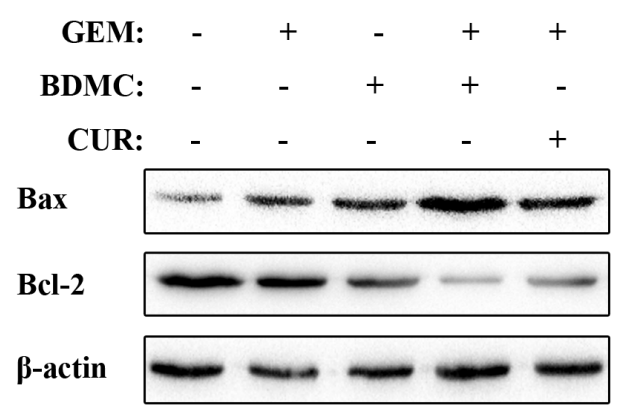

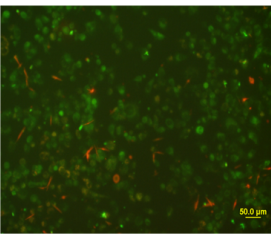

BDMC

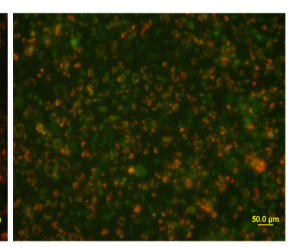

NAC+GEM+BDMC

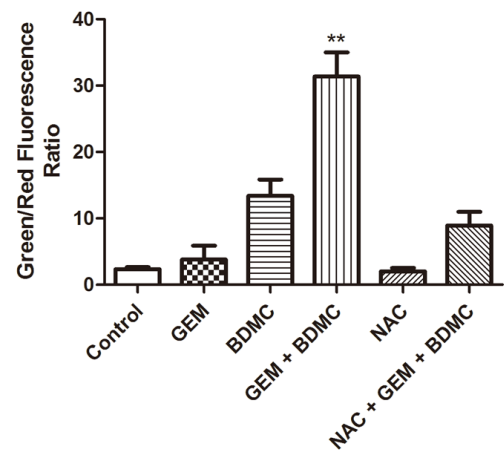

(F)

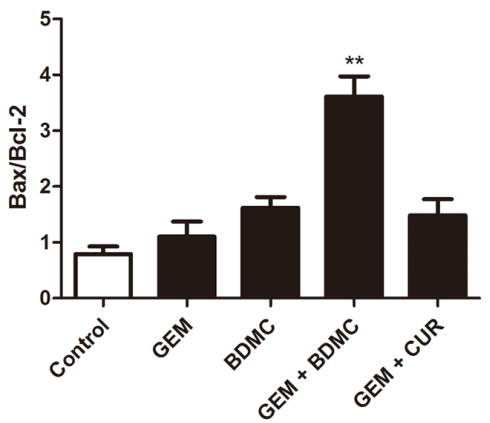

Figure 3: BDMC induces apoptosis through mitochondrial dysfunctions. A. cells were placed together with WST-1 working solution for $3 \mathrm{~min}$ at $37^{\circ} \mathrm{C}$. Intracellular superoxide levels were determined. B. cells were treated with indicated drugs for $24 \mathrm{~h}$. Cell lysates were prepared and reacted with assay solutions for $5 \mathrm{~min}$ at $25^{\circ} \mathrm{C}$. Total GSH was determined by standard curves. C. representative cell images of JC-1 staining. NAC was pre-incubated for $1 \mathrm{~h}$ at $200 \mu \mathrm{mol} / \mathrm{L}$. D. fluorescent intensity of red and green channels was quantified. $\Delta \psi \mathrm{m}$ was calculated as red to green fluorescence ratio. E. Bax and Bcl-2 were detected by western blot. Curcumin was utilized as a comparative drug. F. densitometric study was utilized to quantify protein levels. Values were normalized to $\beta$-actin, and data was shown as means $\pm \mathrm{SD}, \mathrm{n}=3, * * p<0.001$. 
in cells treated with BDMC-GEM (Figure 4(A)). TUNEL assay presented similar results after the pretreatment with NAC (Figure 4(B, C)). These data verified the involvement of oxidative stress in the apoptotic process triggered by BDMC.

\section{2-DE and MS assays identify iconic signaling proteins underlying the BDMC-induced apoptosis}

Representative 2-DE gel images for Control, GEM, and BDMC-GEM groups are shown in Figure 5(A). PDQUEST software was adopted to compare the protein maps. Significantly altered spots were identified as pivotal signaling proteins, and were used to establish a wholeprotein interaction network underlying the molecular mechanism of BDMC-GEM combination. In total, 13 differentially expressed proteins were revealed and shown in Figure 5(B). Detailed information of these signaling proteins was collected and summarized in Table 2.

\section{Protein-protein interaction network analysis reveals the hub protein}

Integrated with six protein-protein interaction databases, 13 signaling proteins identified by MS assay were input into Cytoscape working station to construct a whole-protein network, which was further analyzed for subclusters via BisoGenet. MCODE algorithmic calculations and Prioritizer analysis were performed to evaluate the subclusters and to predict pivotal hubs in the network. By calculating node degree, GRP78 was identified as the most important node with the highest degree in the network (Figure 6(A)). MCODE algorithm
(B)

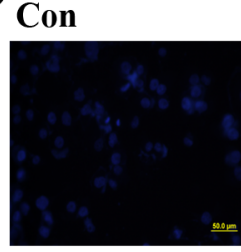

NAC

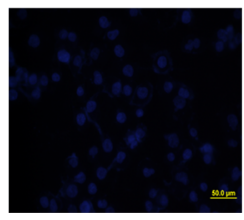

(A)
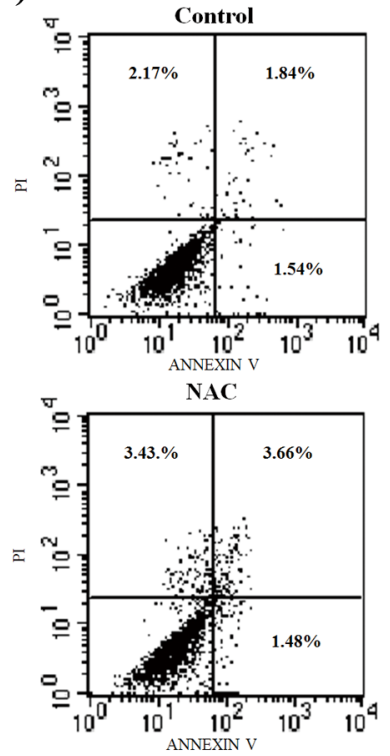

GEM + BDMC
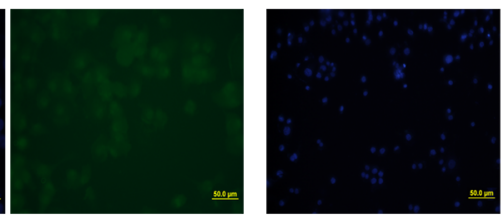

$\mathrm{NAC}+\mathrm{GEM}+\mathrm{BDMC}$

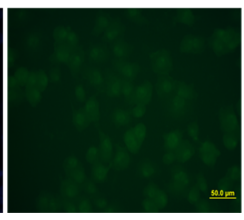

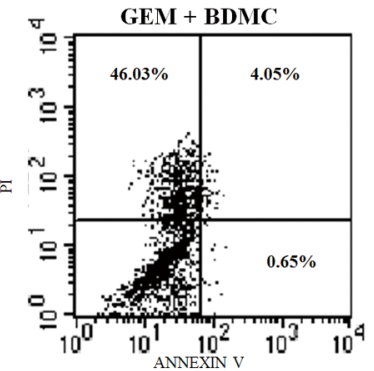

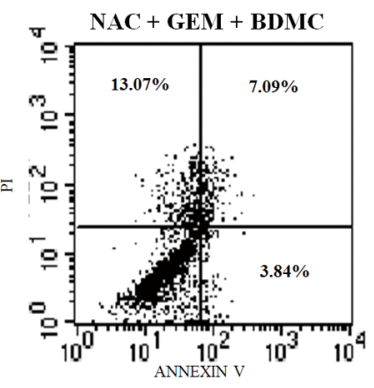

(C)
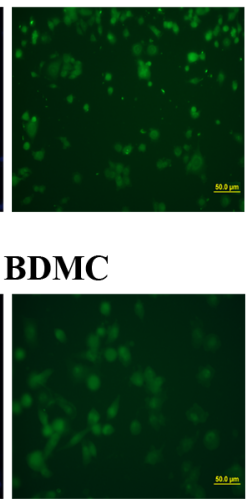

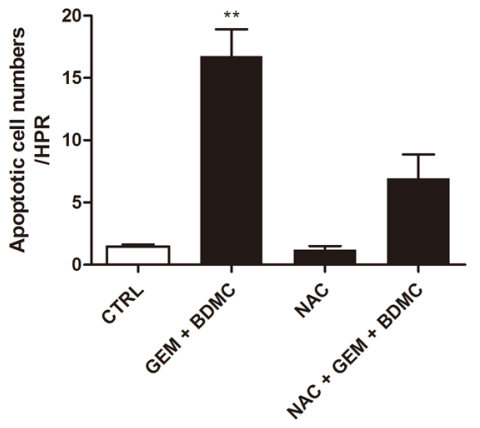

Figure 4: NAC partially reverses BDMC-induced cell death. Cells were incubated in 6-well plates and were treated with BDMCGEM combination for $24 \mathrm{~h}$. NAC was pre-incubated before relevant staining reagents were added. A. cells were detected for apoptosis using PI and Annexin-V. B. representative images of TUNEL staining for detection of cell death. C. TUNEL positive cells were quantified as cell numbers per HPR. Values were shown as mean \pm SD from three independent experiments, ${ }^{* *} p<0.001$. 
(A)

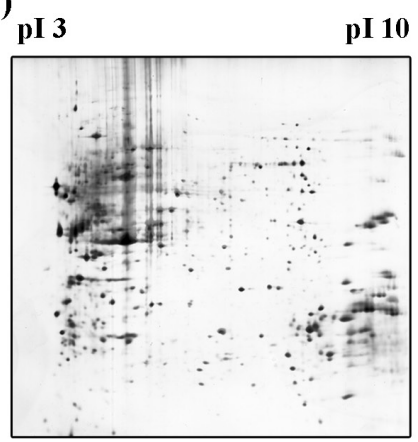

Con

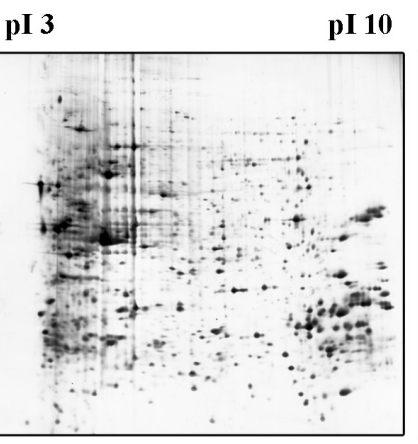

GEM
PI 3

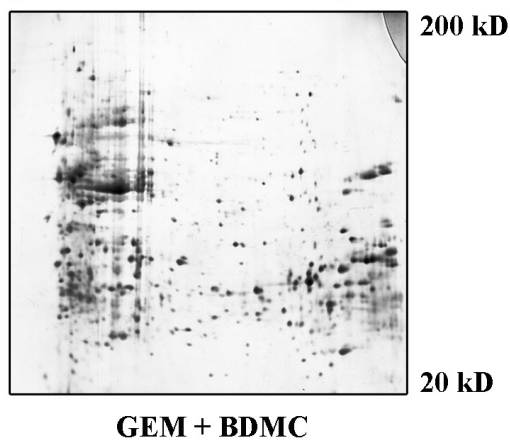

(B)

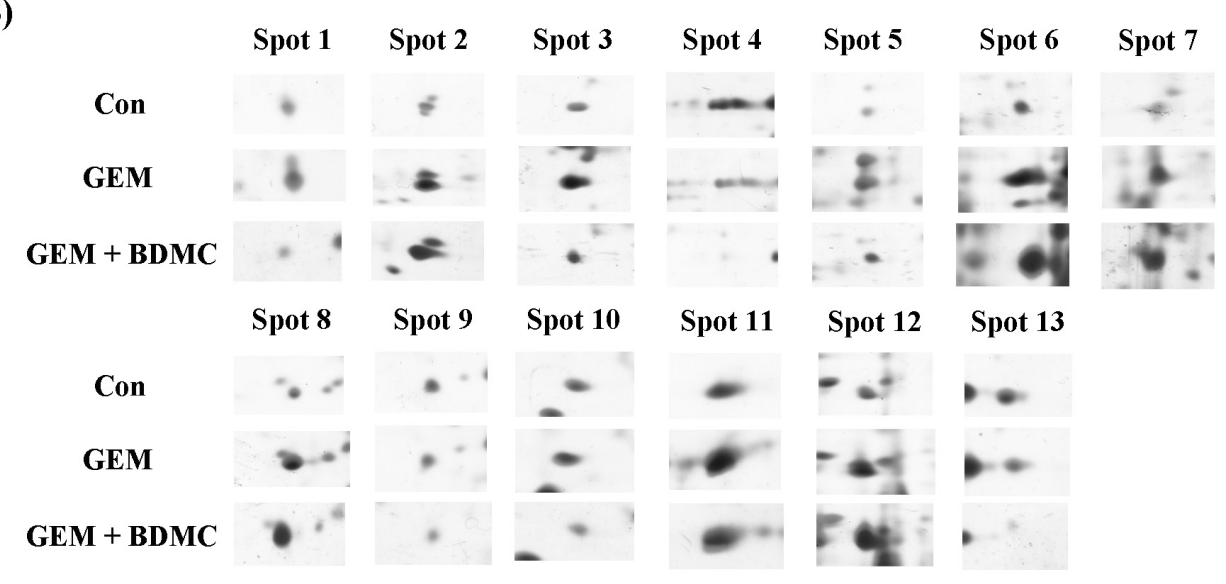

Figure 5: Representative 2-DE gel images. A. representative 2-DE gel images of control, GEM, and BDMC-GEM groups were listed and stained with silver staining solution. B. expanded spots of differentially expressed proteins were identified by MS.

Table 2: List of differentially expressed proteins identified by mass spectrometry

\begin{tabular}{llcccc}
\hline Spot & \multicolumn{1}{c}{ Target Protein Name } & UniProtKB No. & Gene Symbol & Match & Score \\
\hline 1 & Protein DJ-1 & Q99497 & PARK7 & $27 / 29$ & 646 \\
2 & Stress-70 protein, GRP 75 & P38646 & HSPA9 & $13 / 17$ & 543 \\
3 & Lamin-A/C & P02545 & LMNA & $73 / 96$ & 2508 \\
4 & Fibroblast growth factor receptor 3 & P22607 & FGFR3 & $2 / 2$ & 150 \\
5 & Heterogeneous nuclear ribonucleoprotein & P14866 & HNRPL & $7 / 16$ & 123 \\
& Heterogeneous nuclear ribonucleoprotein & 014979 & HNRDL & $5 / 6$ & 98 \\
6 & D-like & & & & 249 \\
7 & Mitochondrial import inner membrane & Q3ZCQ8 & TIM50 & $11 / 14$ & 249 \\
8 & translocase subunit TIM50 & P11021 & HSPA5 & $35 / 61$ & 1018 \\
9 & 78kD glucose-regulated protein, GRP78 & P35232 & PHB & $13 / 18$ & 283 \\
10 & Prohibitin & P07355 & ANXA2 & $18 / 24$ & 462 \\
11 & Annexin A2 & P78371 & CCT2 & $12 / 17$ & 208 \\
12 & Pyruvate kinase isozymes & P14618 & PKM & $23 / 30$ & 651 \\
13 & Malate dehydrogenase, mitochondria & P40926 & MDHM & $95 / 110$ & 2888 \\
\hline
\end{tabular}


recognized three major subclusters, among which subcluster 1 showed the highest score (Figure 6(B, C)).

Via Prioritizer plugin, the indicated network was screened in parallel for six parameters, namely Generalized Random Walk Receiver Closeness, Generalized Shortest Path Closeness, Generalized Random Walk Betweenness, Generalized Degree Centrality, Generalized Random
Walk Transmitter Closeness, and Generalized Shortest Path Betweenness. The ranking of hub proteins under all parameters were accordingly created and shown in Table 3. CUL3 and UBC were two genes occurred across all top-five rankings. By integrating with MS results, two optimized minimum networks converged with CUL3 (Figure 6(D), left) and UBC (Figure 6(D), right) were
(A)

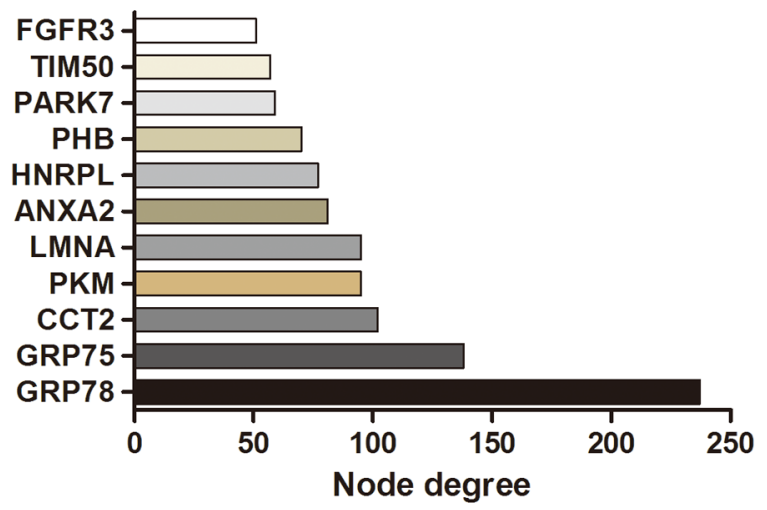

(B)

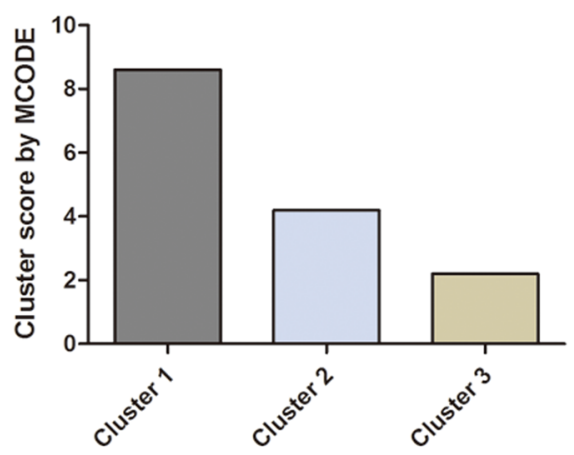

(C)

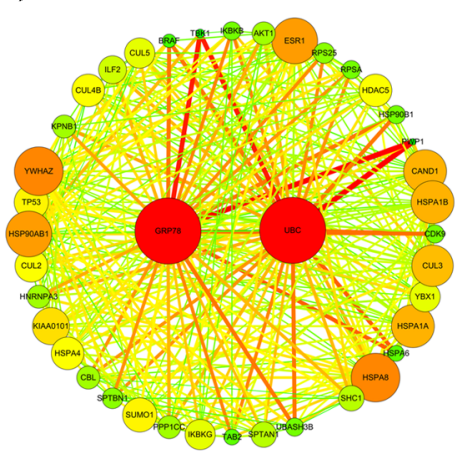

Cluster 1

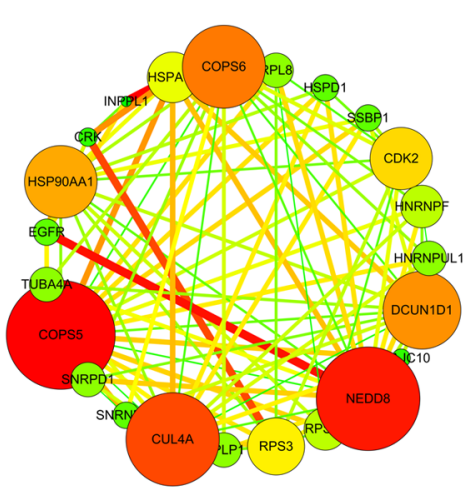

Cluster 2

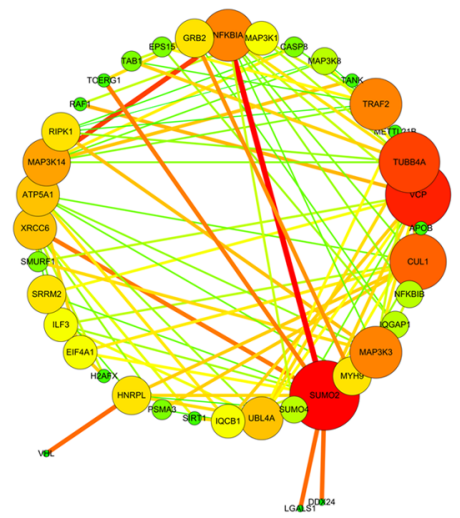

Cluster 3

(D)

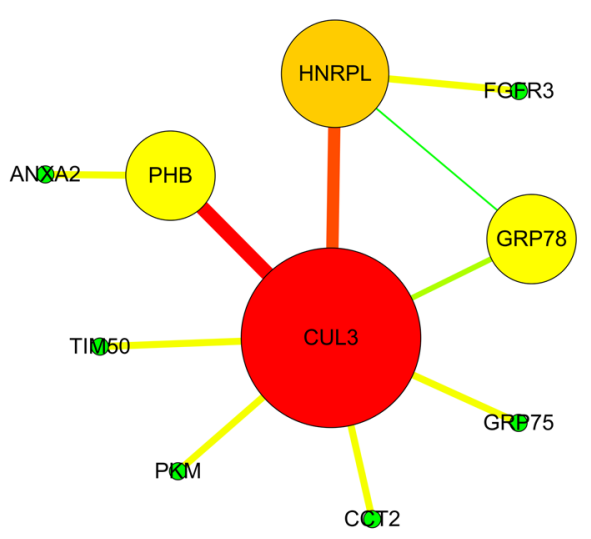

Optimized network of CUL3
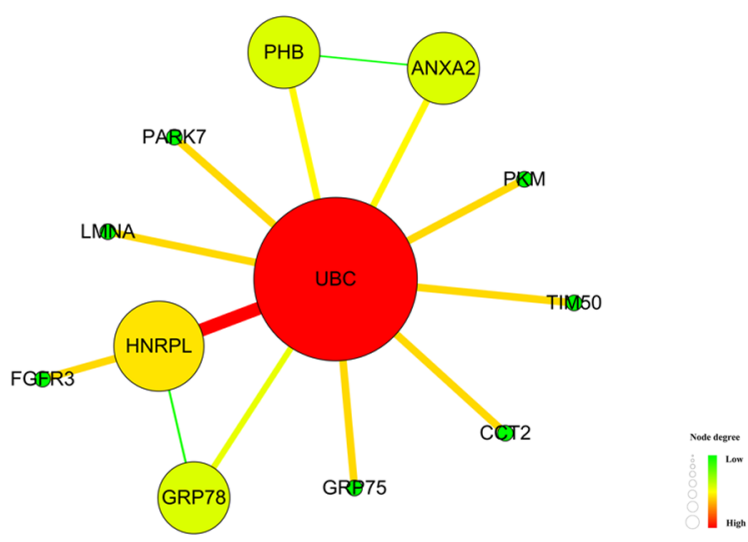

Optimized network of UBC

Figure 6: Protein-protein interaction network construction. A whole-protein interaction network was established. A. node degree of each signaling protein was calculated. B. MCODE scores of three subclusters were determined by MCODE algorithm. Subcluster-1 presented the highest score. C. three subclusters were shown here. D. optimized minimum networks of CUL3 and UBC were respectively created. 
Table 3: Rankings of possible hub proteins identified by BisoGenet

\begin{tabular}{lcccccc}
\hline Rank & $\begin{array}{c}\text { Generalized } \\
\text { Random Walk } \\
\text { Receiver Closeness }\end{array}$ & $\begin{array}{c}\text { Generalized } \\
\text { Shortest Path } \\
\text { Closeness }\end{array}$ & $\begin{array}{c}\text { Generalized } \\
\text { Random Walk } \\
\text { Betweenness }\end{array}$ & $\begin{array}{c}\text { Generalized } \\
\text { Degree } \\
\text { Centrality }\end{array}$ & $\begin{array}{c}\text { Generalized Random } \\
\text { Walk Transmitter } \\
\text { Closeness }\end{array}$ & $\begin{array}{c}\text { Generalized } \\
\text { Shortest Path } \\
\text { Betweenness }\end{array}$ \\
\hline 1 & UBC* & UBC & UBC & UBC & UBC & UBC \\
2 & SPTAN1 & CUL3 & GRB2 & HSPA8 & CUL3 & SUMO2 \\
3 & CUL3 $*$ & FN1 & CUL3 & CUL3 & SUMO2 & HSP90AA1 \\
4 & SUMO2 & SUMO1 & APP & ESR1 & SPTAN1 & CUL3 \\
5 & ESR1 & YWHAZ & HSP90AB1 & HSP90AA1 & ESR1 & HSP90AB1 \\
\hline
\end{tabular}

* Gene symbols that occurred across all six rankings

constructed respectively. Such optimized networks are purely composed of protein nodes that link to each other by single edge or by only one intermediate partner.

\section{BDMC upregulates GRP78 and triggers cell transition from ER stress to apoptosis through eIF2 $\alpha /$ CHOP pathway}

To examine the results proposed by the bioinformatics analysis, we investigated the signaling proteins by western blot assays. In consistency with 2-DE data, we observed a significant upregulation of GRP78 in cells treated with BDMC alone or together with GEM (Figure 7(A)). Cullin3, the other key node indicated by the network analysis, is meaningfully downregulated by BDMC in PANC-1 cells. Eukaryotic translation initiation factor alpha (eIF2 $\alpha$ ) constitutes the essential pathway underlying the unfolded protein response (UPR) $[14,15]$. We found that the phosphorylation of eIF2 $\alpha$ was significantly increased by BDMC (Figure 7(B, C-right)). Furthermore, we observed an enhanced expression of $\mathrm{C} /$ EBP homologous protein (CHOP) in cells treated with BDMC alone or together with GEM (Figure 7(B, C-left)). Together, these results suggest that BDMC upregulates GRP78 and transfers cells from ER stress to apoptosis through eIF $2 \alpha / \mathrm{CHOP}$ pathway.

\section{BDMC offsets GEM-induced chemoresistance in pancreatic cancer cells}

As suggested in the network construction, the optimized minimum networks pinpoint three chemoresistance markers, namely protein DJ-1, annexin-A2, and prohibitin, which have shown close relationship to chemoresistance in various types of cancer [16-18]. As demonstrated in Figure 7(A), $\mathrm{DJ}-1$, annexin-A2, and prohibitin were significantly downregulated by BDMC alone or combined with GEM. This was consistently detected by the MS assays shown in Figure 5. These data indicate that BDMC counteracts the chemoresistance induced by gemcitabine in pancreatic cancer cell.

\section{A GRP78-dependent pathway was revealed}

Expression of GRP78 was shown in Figure 8(A) after the transient transfection of siRNA. To investigate whether the downregulations of Cullin3, Annexin-A2, DJ-1 and Prohibitin were dependent on GRP78, we compared their expressions in BDMC-GEM-treated cells with and without GRP78 siRNA. Cullin3, annexin-A2, and DJ-1 showed significant changes in expression levels, and were thereby revealed as the downstream molecules of GRP78 (Figure 8(B)). However, the inhibition of prohibitin was independent on GRP78 (Figure 8(C)).

\section{GRP78 siRNA partially reverses BDMC-GEM- induced apoptosis in pancreatic cancer cells}

For rescue experiments, we examined the viability of MiaPaCa-2 and PANC-1 cells transfected with GRP78 siRNA. The results showed that GRP78 siRNA partially reversed the BDMC-GEM-induced apoptosis by approximately $35 \%$ in MiaPaCa-2 cells (Figure 8(D), left) and $25 \%$ in PANC-1 cells (Figure $8(\mathrm{D})$, right).

Taken together, our results reveal that BDMC induces mitochondrial dysfunctions in pancreatic cancer cells, and facilitates apoptosis through a GRP78-dependent pathway (Figure 9). Thus, we propose BDMC for further clinical studies to treat pancreatic cancer.

\section{DISCUSSION}

Here, we have shown that BDMC, a derivative of curcumin, is significantly more effective in promoting apoptosis in gemcitabine-resistant pancreatic cancer cells in comparisons with other curcuminoids, and we elucidate its specific mechanisms. Initially, this could be due to the induction of mitochondrial dysfunctions and abnormal oxidative-stress response in cells treated with BDMC. Oxidative stress refers to an intracellular situation of an imbalance between pro-oxidant and antioxidant factors. It causes cellular damage that is primarily generated from mitochondria [10]. Mitochondrial defects lead to imbalanced 
redox environments within cells, eliciting abnormal oxidative-stress response that either activates severe mitochondrial pathogenesis or triggers DNA damage [19], cellular damage [20], and/or other apoptotic events [21]. Curcumin, a natural chemopreventive agent that is nontoxic but highly effective in killing cancer cells, has shown multi-targeted characteristics [22, 23], including disrupting redox balance in tumor cells [24]. In line with this, our results elucidate that BDMC causes an increased level of intracellular superoxide anions as well as a reduction in total GSH content in cells treated with either BDMC alone or combined with gemcitabine. Also, we observe that BDMC brings about a significant reduction in mitochondrial membrane potential and a meaningfully increased ratio of $\mathrm{Bax}$ to $\mathrm{Bcl}-2$. Bax and $\mathrm{Bcl}-2$ partially locate on mitochondrial membrane and are closely related to cell death and survival. These data indicate that mitochondrial dysfunctions and an imbalanced redox condition are induced in the cells treated with BDMC. The hypothesis that BDMC inhibits PANC-1 cell viability through redox stress is also evidenced by the

(A)
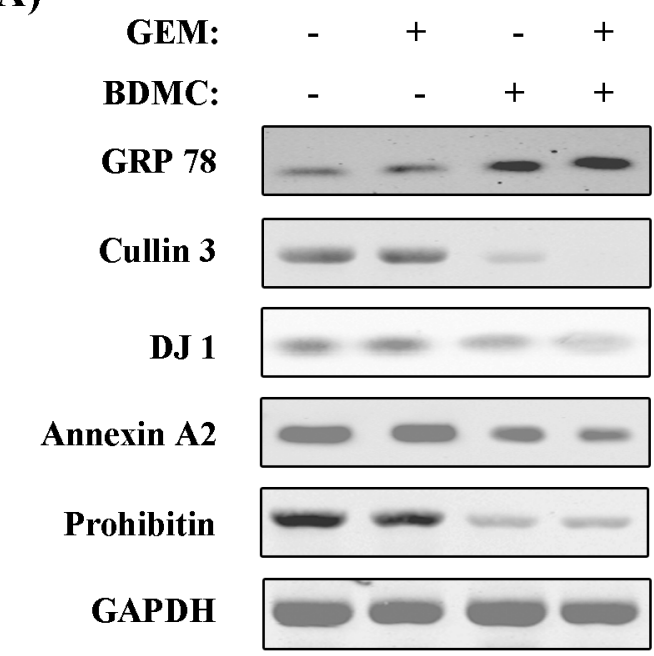

(C)

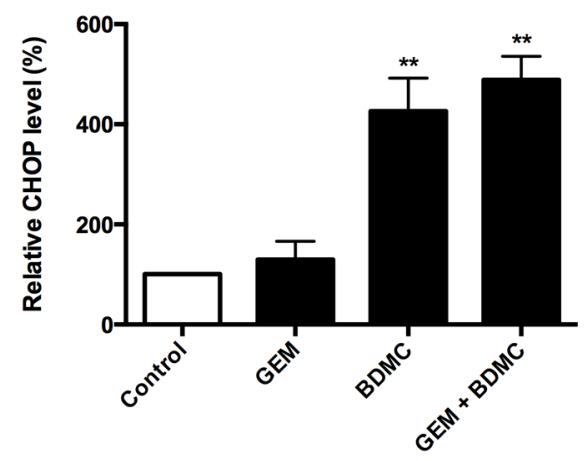

rescue experiments utilizing NAC pre-treatment. These results thereby suggest that BDMC induces cell death via mitochondrial dysfunctions and oxidative stress in human pancreatic cancer cells.

Pathological stimuli such as DNA damage and oxidative stress impede endoplasmic reticulum (ER) functions, resulting in the accumulation of unfolded proteins and then ER stress in cells. It is known that oxidative stress and ER stress are interlinked via multiple pathways including redox imbalance and reactive oxygen species (ROS) overproduction $[25,26]$. GRP78, an ERlocated chaperon, mediates essential components of ER stress-induced apoptosis, and is considered as an ERstress marker [27, 28]. Significantly upregulated GRP78 indicates the inductions of Unfolded Protein Response (UPR) and ER stress [29]. Here, our results show for the first time that BDMC upregulates GRP78 in GEMresistant PANC-1 cells, which consistently has been elucidated by MS and the following immunoblotting assays. Furthermore, cancer cells progressing towards UPR and ER stress provide either survival or cell

(B)
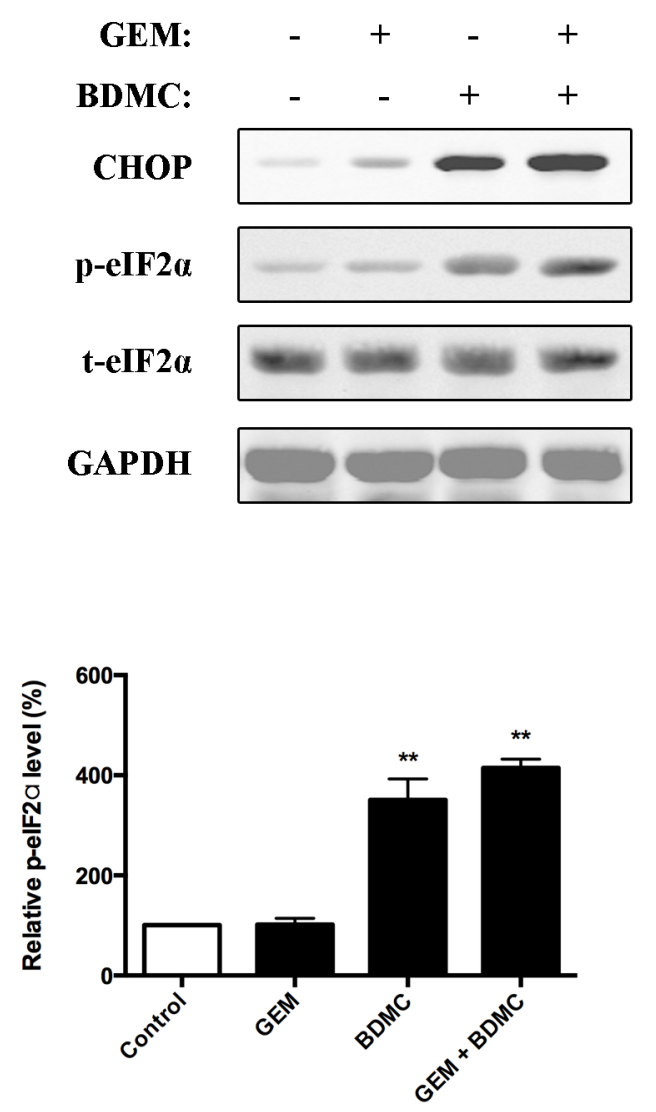

Figure 7: Evaluations on protein interaction network. A. immunoblotting analysis on GRP78, Cullin 3, DJ-1, Annexin A2, Prohibitin and GAPDH in cells treated with GEM, BDMC, and the combination. B. expression levels of CHOP, p-eIF2 $\alpha$ and t-eIF2 $\alpha$ were determined. C. densitometric analysis was used to quantify the levels of CHOP and p-eIF2 $\alpha$. Values were normalized to GAPDH. Data was shown as mean $\pm \mathrm{SD}$ from three independent experiments, $* * p<0.001$. 
death signals, which primarily depends on the extent of ER stress occurred in cells [14, 30]. Cells exposed to moderate ER stress can avoid apoptosis by undergoing UPR or by activating autophagy [31], while cells exposed to severe and protracted ER stress tend to launch programmed apoptosis via multiple steps [27], wherein CHOP is a well-characterized marker for the cell transition from ER stress to apoptosis [30, 32]. Recent research also suggests that pharmacological interventions inducing prolonged ER stress may be targeted for cancer therapy $[33,34]$. We observe that BDMC meaningfully increases CHOP and activates the phosphorylation of eIF $2 \alpha$. These together suggest that BDMC causes ER stress and eventually triggers the cell transition from ER stress to apoptosis, which may partially correlate with the mitochondrial dysfunction and oxidative stress induced by BDMC.

By integrating MS data with bioinformatics resources, several chemoresistance-related targets are identified and further studied to fully understand the antitumor effects of BDMC. Cullins are a family of proteins that confer substrate specificity to the multimeric

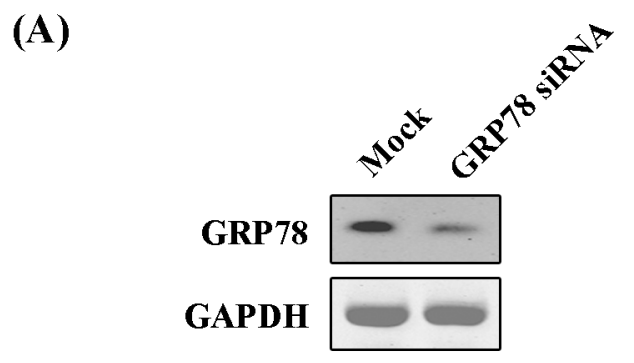

(B)

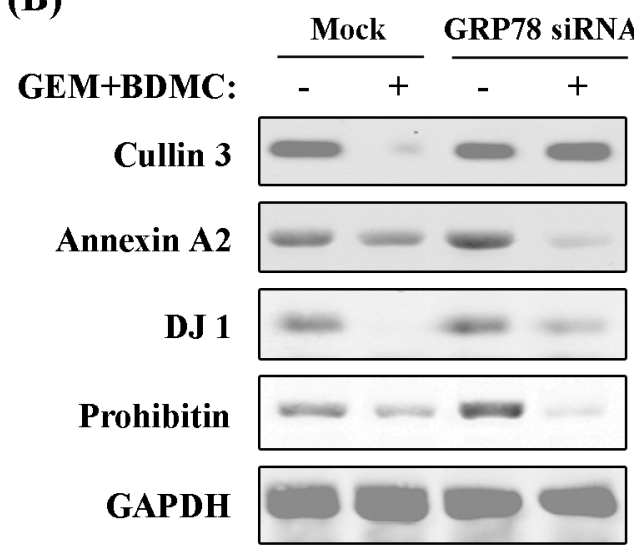

(D)

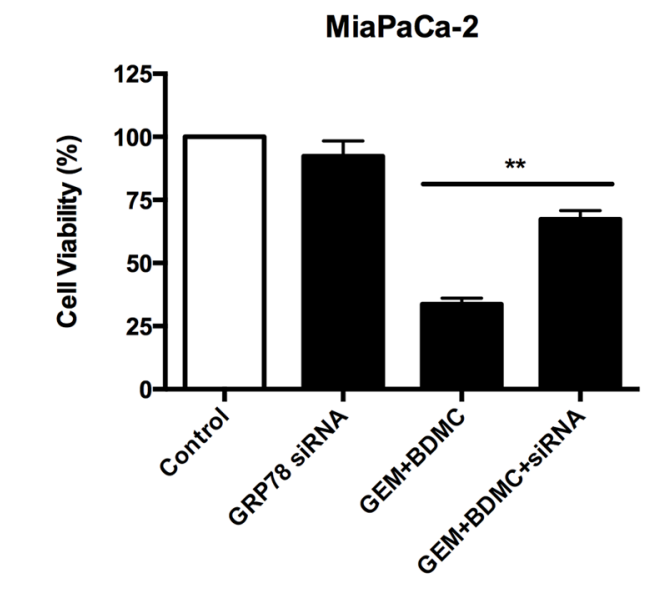

(C)
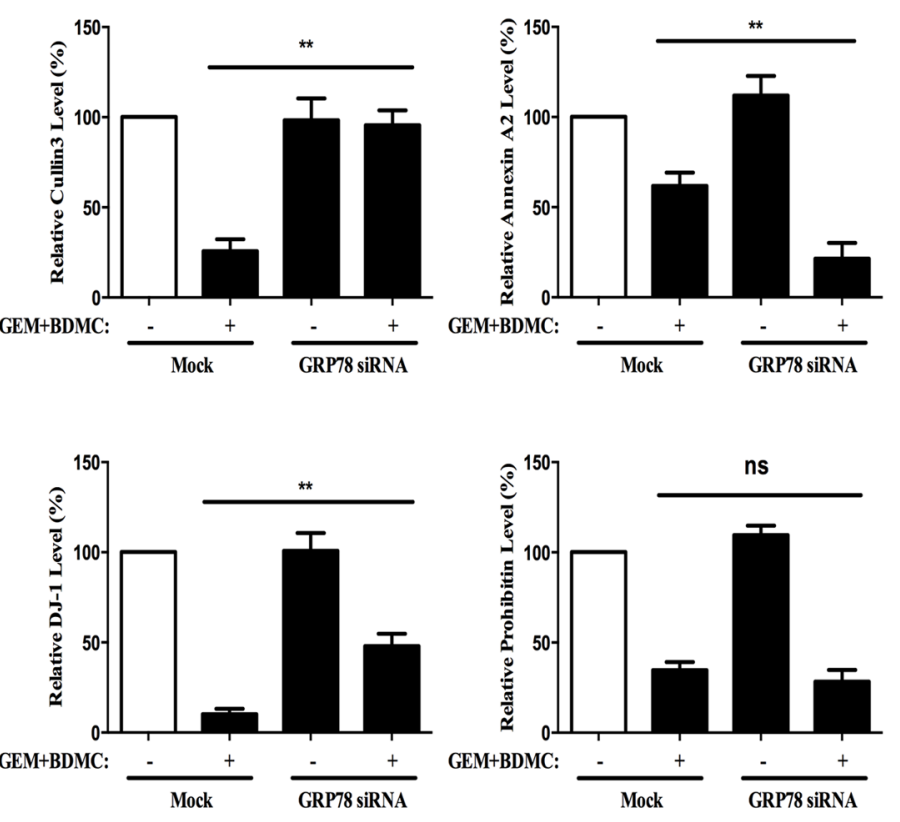

PANC-1

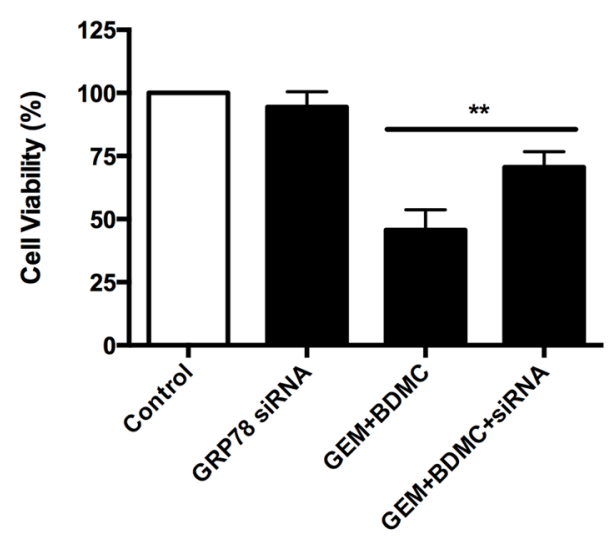

Figure 8: A GRP78-dependent pathway was revealed. A. GRP78 expression was evaluated after siRNA administration. B. western blots of Cullin3, Annexin A2, DJ-1, and Prohibitin were presented. C. densitometric analysis was utilized to quantify the protein content. Values were normalized to GAPDH and were compared with control group; ns, no significant difference. D. cell viability was determined in MiaPaCa-2 and PANC-1 cells, respectively. Data was shown as mean $\pm \mathrm{SD}$ from three independent experiments, ${ }^{* *} p<0.01$. 


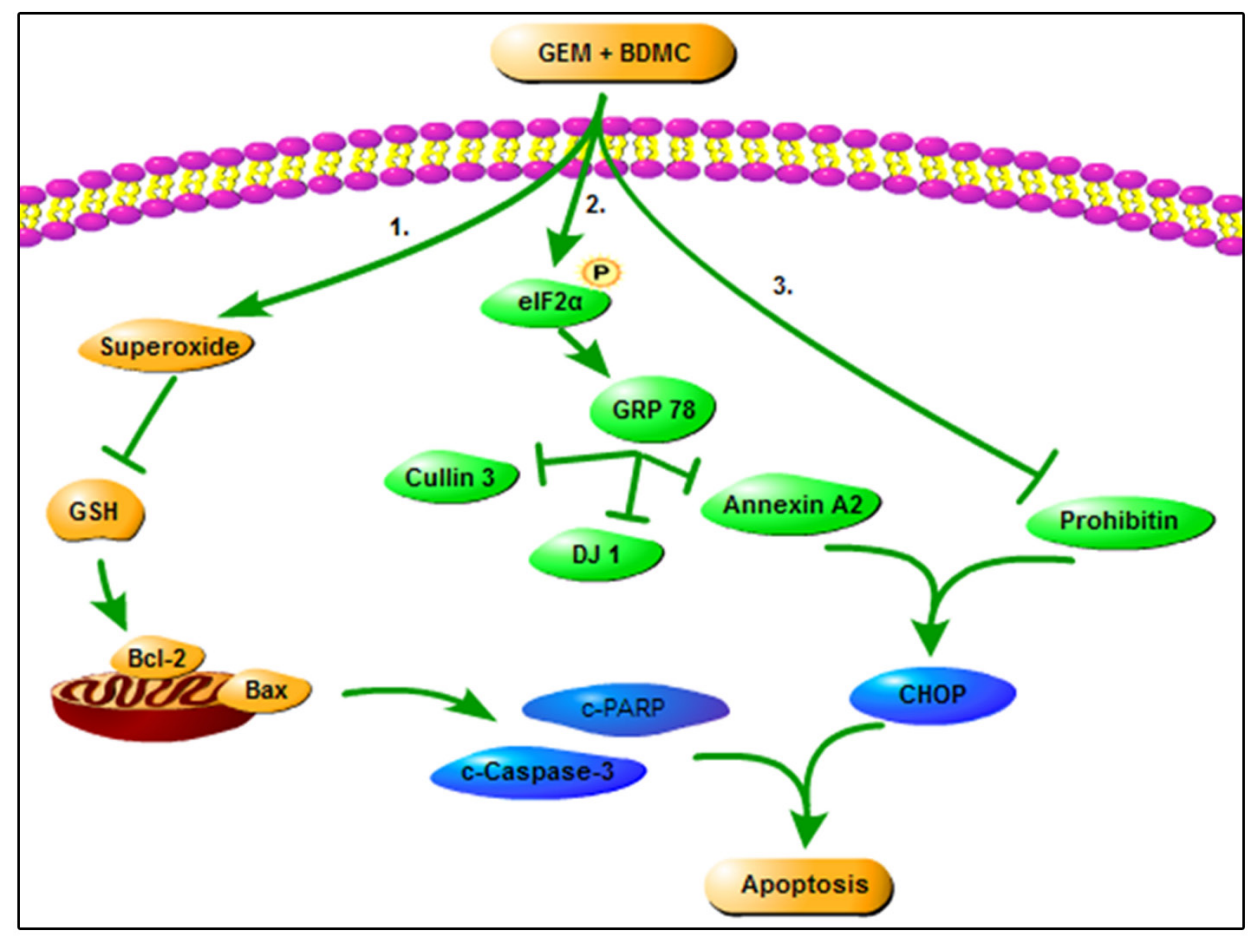

Figure 9: The role of BDMC in sensitizing GEM. On one hand, BDMC promotes cell death by inducing mitochondrial dysfunction, activates GRP78, and facilitates cell transition from ER stress to apoptosis. On the other hand, BDMC inhibits DJ-1 and prohibitin, and dispels GEM-induced chemoresistance in pancreatic cancer cell.

complex of E3 ligases acting as scaffold proteins. Interestingly, distinguished from other family members, cullin3 has been implicated to have a special relationship with redox homeostasis and intracellular stress responses [35]. Cullin3 has been targeted to develop therapeutic strategies for redox disorders. Besides, recent research has shown that cullin 3 correlates with cancer progression and is evidenced as a promising target to treat human cancers $[36,37]$. Notably, cullin 3 is significantly overexpressed within cancer sites but remains undetectable in normal tissues [38]. Here, we discover that cullin3 is noticeably downregulated in cells treated with either BDMC alone or together with GEM. Depletion of GRP78 significantly prevents the inhibition of cullin3, suggesting cullin3 inhibition is dependent on the activation of GRP78 by BDMC. In light of the above bioinformatics analysis, GRP78 and cullin3 collocate in the same minimum protein network (Figure 6(D)). Besides, GRP78 is presented with a relatively higher node degree which is indicated in a dark yellow tag in the optimized network of CUL3. Together, these results strongly indicate that potential interplays between GRP78 and cullin3 may occur in the intracellular stress responses induced by BDMC. Of note, the above results highlight that $\mathrm{BDMC}$ inhibits cullin3 in pancreatic cancer cells, which is dependent on the activation of GRP78.

Additionally, DJ-1 and prohibitin, which have been extensively reported to closely correlate with chemoresistance and to overexpress within cancer sites [16-18], are both suppressed in cells treated with BDMC alone or combined with GEM. The downregulation of DJ-1 could be significantly reversed by depletion of GRP78. However, the difference of prohibitin content between siRNA +/- groups is not meaningful, indicating that the inhibition of prohibitin by BDMC is GRP78independent. Annexin A2 is an inducible, calciumdependent phospholipid-binding protein, and is also overexpressed in a variety of human malignancies [39, 40]. Recent studies have shown that curcumin potentially inhibits Annexin A2 in cancer tissues [41]. Here, our results show that Annexin A2 is differentially expressed in response to GEM alone and BDMC-GEM combination. We demonstrate that BDMC represses Annexin A2 in pancreatic cancer cells, which is also dependent on GRP78 activation. Taken together, these results elucidate that BDMC offsets the chemoresistance induced by gemcitabine in human pancreatic cancer cells.

To summarize, compared with curcumin and DMC, BDMC possesses the greatest efficacy in sensitizing gemcitabine in pancreatic cancer cells. On one hand, $\mathrm{BDMC}$ causes mitochondrial dysfunctions and triggers a GRP78-dependent pathway to directly promote apoptosis; on the other hand, it eliminates the chemoresistance induced by gemcitabine. Herein, we propose BDMCGEM combination regimen as a better solution to treat pancreatic cancer. 


\section{MATERIALS AND METHODS}

\section{Reagents and cell culture}

Gemcitabine, Curcumin, DMC and BDMC were from Sigma-Aldrich Corporation (St. Louis, MO, USA). Anti Bcl-2, Bax, Activated-Caspase-3, Activated-PARP, GRP78 and CHOP antibodies were from Bioworld Technology, Inc. (Louis Park, MN, USA). Antibody to Cullin3 was from US Bio (MA, USA), and antibodies to Annexin A2, Prohibitin, p-eIF2 $\alpha$ and eIF2 $\alpha$ were obtained from Cell Signaling Technology, Inc. (Danvers, MA, USA). Unless specifically indicated, all other biochemical reagents were obtained from Amresco (Solon, OH, USA). PANC-1 and MiaPaCa-2 cell lines were from Cell Culture Center, Institute of Basic Medical Science, Chinese Academy of Medical Sciences (Beijing, China). Briefly, PANC-1 and MiaPaCa-2 cells were cultured in DMEM medium supplemented with $10 \%$ fetal bovine serum (FBS; Hyclone, Logan, Utah, USA) in a humid atmosphere incubator with $5 \% \mathrm{CO}_{2}$ at $37^{\circ} \mathrm{C}$. Cells were treated with drugs or vehicles after growing to $70 \%$ to $80 \%$ confluence.

\section{Cell viability assay}

Cell viability was measured by a commercial MTS assay kit (Promega, Fitchburg, Wisconsin, USA). Cells were seeded into 96-well plates at a density of 4,000 cells/ well. Drug treatments of indicated concentrations were added for 24 hours. The absorbance was determined at $490 \mathrm{~nm}$ by a micro-plate reader (Thermo Scientific, Menlo Park, CA, USA) 4 hours after the probe reagents had been added.

\section{Flow cytometric analysis}

Cells were diluted to $8 \times 10^{4} / \mathrm{ml}$ and incubated for $48 \mathrm{~h}$ at $37^{\circ} \mathrm{C}$ in 6 -well plates. Cells were then treated with control solvent $(0.1 \%$ DMSO), GEM $(25 \mathrm{nmol} / \mathrm{L})$, BDMC $(10 \mu \mathrm{mol} / \mathrm{L})$ alone or their combination for 24 hours. Cells were collected, washed in PBS, and were resuspended in $100 \mu$ l binding buffer containing $5 \mu$ of Annexin V-FITC (Pharmingen, San Diego, CA) and $5 \mu l$ of PI (Pharmingen, San Diego, CA). Samples were mixed gently and incubated at room temperature in dark for $20 \mathrm{~min}$. $500 \mu \mathrm{l}$ binding buffer was then added to each sample tube. Samples were analyzed by FACS (Beckman Coulter, CA). A minimum of 10,000 cells within gated region were collected.

\section{TUNEL staining}

Apoptosis was measured using in situ cell-death detection kit (G3250, Promega, Madison, USA) as we previously described [42]. Terminal deoxynucleotidyl transferase biotin-dUTP nick end labeling (TUNEL) staining was performed according to the manufacturer's instructions. TUNEL-positive cells were indicated in green fluorescence in Figures 2(D) and 4(B).

\section{Measurement of intracellular superoxide and total GSH levels}

Cells were seeded into 6-well plates, and were incubated for 24 hours. Commercial intracellular superoxide and t-GSH kits (Beyotime, Beijing, China) were utilized to determine the levels of intracellular SOD and t-GSH. According to manufacturer's brochure, the values were measured by a micro-plate reader (Thermo Scientific, Menlo Park, CA, USA) for quantifications.

\section{Determination of mitochondrial membrane potential $(\Delta \psi \mathrm{m})$}

JC-1 fluorescent probe kit (Beyotime, Beijing, China) was used to determine $\Delta \psi \mathrm{m}$. Briefly, cells were incubated in DMEM media containing JC-1 $(5 \mu \mathrm{g} /$ $\mathrm{ml}$ ) for $30 \mathrm{~min}$ at $37^{\circ} \mathrm{C}$, and were then measured by fluorescent microscope (Carl Zeiss, Axiovert 200). $\Delta \psi \mathrm{m}$ was determined by MPF-66 fluorescence spectrometer (Perkin-Elmer) with excitation wavelength at $490 \mathrm{~nm}$ and emission wavelength at $530 / 590 \mathrm{~nm}$. The ratios of readings at according wavelengths were converted into relative $\Delta \psi \mathrm{m}$ values.

\section{Two-dimensional gel electrophoresis and mass spectrometry identification}

Cells were randomly divided into three groups: control, GEM (25nmol/L, $24 \mathrm{~h})$, and BDMC-GEM $(10 \mu \mathrm{mol} / \mathrm{L}$ BDMC, $25 \mathrm{nmol} / \mathrm{L}$ GEM, $24 \mathrm{~h}) .2-\mathrm{DE}$ and MS assays were performed as we previously described [43]. Cells were collected, washed with PBS, and subsequently centrifuged for $1 \mathrm{~min}$ at $2,500 \mathrm{~g}$. Cell pellets were dissolved in RIPA lysis buffer, and were ultra-sonicated (ten strokes, low amplitude) on ice for homogenization. Lysed cells were centrifuged at $15,000 \mathrm{~g}$ for $30 \mathrm{~min}$ at $4^{\circ} \mathrm{C}$. Supernatant containing solubilized proteins was used for 2-DE and MS experiments. Bio-Rad 2-DE system was utilized, and $200 \mu \mathrm{g}$ protein sample was applied for IEF using ReadyStrip IPG Strips (17cm, pH 4-7) (BioRad). The strips were placed into Protein IEF (Bio-Rad), and were rehydrated at $50 \mathrm{~V}$ for $12 \mathrm{~h}$. Proteins were thus separated by $p I$ values. IPG strips were then equilibrated and directly applied for $12 \%$ homogeneous SDS-PAGE gels electrophoresis using PROTEIN II xi Cell System (Bio-Rad). Gels were stained using Silver Stain Plus Kit reagents (Bio-Rad). Protein samples were obtained from three independent experiments. Stained gels were scanned by Densitometer GS-800 (Bio-Rad) and were analyzed via PD-Quest software (Bio-Rad). Protein spots were 
excised from gels with EXQuest Spot Cutter (Bio-Rad) for following MS identifications using ABI 4700 Proteomics Analyzer (Framingham, MA, USA).

\section{Protein-protein interaction network construction}

Protein-protein interaction information from six publicly available databases including Human Protein Reference Database [44], Molecular Interaction database [45], IntAct [46], Database of Interacting Proteins [47], Biogrid [48], and MIPS [49] was integrated as we previously described $[50,51]$. Signaling hub proteins indicated by MS studies as well as their proteininteraction database information were integrated and input into BisoGenet and Cytoscape Working Platforms to expand and construct their corresponding wholeprotein network. To further nail down specific clusters correlated to BDMC-GEM combination, MCODE algorithm and Prioritizer plugin were adopted. Nonassociated intermediate nodes were removed. Optimized minimum networks containing key hubs were thereby constructed.

\section{Cell transfection and GRP78 RNAi assays}

Commercial GRP78 siRNA was obtained from Santa Cruz Biotechnology, Inc. (Santa Cruz, CA, USA). GRP78 siRNA at a concentration of $100 \mathrm{nmol} / \mathrm{L}$ was transiently transfected into PANC-1 cells with Lipofectamine-2000 reagent (Invitrogen, Carlsbad, CA, USA). After incubation for 24 hours, PANC-1 cells were harvested for further experiments.

\section{Immunoblot assays}

PANC-1 cells were harvested and lysed in RIPA buffer containing PMSF (phenylmethylsulfonyl fluoride) and protease inhibitor cocktail (Calbiochem, San Diego, CA, USA). Following centrifugation at 12,000g for $15 \mathrm{~min}$ at $4^{\circ} \mathrm{C}$, supernatants were collected. Protein concentration was measured by bicinchoninic acid (BCA) assay kit (Thermo Scientific Pierce, Rockford, IL, USA). Protein samples $(80 \mu \mathrm{g})$ were separated by $12 \%$ sodium dodecyl sulfate-polyacrylamide gel (SDS-PAGE). Upon completion of electrophoresis, proteins were transferred to PVDF membrane. Membranes were then incubated with $5 \%$ skimmed milk in Tris-buffered saline Tween (TBS-T, $20 \mathrm{mmol} / \mathrm{L}$ Tris, $137 \mathrm{mmol} / \mathrm{L} \mathrm{NaCl}, \mathrm{pH} 7.6$ ) for overnight at $4{ }^{\circ} \mathrm{C}$ with primary antibodies. After washed three times with TBS-T buffer, membranes were incubated with Alexa Fluor secondary antibodies (Cell Signaling Technology, Inc., Danvers, MA, USA), and were then scanned by Odyssey Image System (LI-COR Biosciences, Nebraska, USA). Band intensity was analyzed by Bio-Rad Quantity One Software (version 4.4.0; Bio-Rad, Hercules, CA, USA) for quantifications.

\section{Data and statistical analysis}

All values are expressed as means \pm SD. For multiple comparisons, statistical analysis was performed using one-way analysis of variance (ANOVA) and Newman-Keuls multiple comparison tests. A value of $p<$ 0.05 was considered statistically significant.

\section{ACKNOWLEDGMENTS}

We deeply thank Dr. Min Ye for the generous help in acquiring the preliminary compounds for the study.

\section{CONFLICTS OF INTEREST}

The authors declare no conflict of interest.

\section{GRANT SUPPORT}

This work was supported by the National Natural Science Foundation of China (No. 81473235, 81673453, $91129727,81673486,81270049,81373405)$ and the Research Fund from Ministry of Education of China (111 Projects No. B07001).

\section{REFERENCES}

1. Hung SW, Mody HR and Govindarajan R. Overcoming nucleoside analog chemoresistance of pancreatic cancer: a therapeutic challenge. Cancer Lett. 2012; 320:138-149.

2. Burris HA, 3rd, Moore MJ, Andersen J, Green MR, Rothenberg ML, Modiano MR, Cripps MC, Portenoy RK, Storniolo AM, Tarassoff P, Nelson R, Dorr FA, Stephens $\mathrm{CD}$ and Von Hoff DD. Improvements in survival and clinical benefit with gemcitabine as first-line therapy for patients with advanced pancreas cancer: a randomized trial. J Clin Oncol. 1997; 15:2403-2413.

3. Mini E, Nobili S, Caciagli B, Landini I and Mazzei T. Cellular pharmacology of gemcitabine. Ann Oncol. 2006; 17 Suppl 5:v7-12.

4. Kamat AM, Tharakan ST, Sung B and Aggarwal BB. Curcumin potentiates the antitumor effects of Bacillus Calmette-Guerin against bladder cancer through the downregulation of NF-kappaB and upregulation of TRAIL receptors. Cancer Res. 2009; 69:8958-8966.

5. Ali S, Ahmad A, Banerjee S, Padhye S, Dominiak K, Schaffert JM, Wang Z, Philip PA and Sarkar FH. Gemcitabine sensitivity can be induced in pancreatic cancer cells through modulation of miR-200 and miR-21 expression by curcumin or its analogue CDF. Cancer Res. 2010; 70:3606-3617.

6. Hao F, Kang J, Cao Y, Fan S, Yang H, An Y, Pan Y, Tie L and Li X. Curcumin attenuates palmitate-induced apoptosis in MIN6 pancreatic beta-cells through PI3K/Akt/FoxO1 
and mitochondrial survival pathways. Apoptosis. 2015; 20:1420-1432.

7. Nagaraju GP, Zhu S, Wen J, Farris AB, Adsay VN, Diaz R, Snyder JP, Mamoru S and El-Rayes BF. Novel synthetic curcumin analogues EF31 and UBS109 are potent DNA hypomethylating agents in pancreatic cancer. Cancer Lett. 2013.

8. Belluti S, Basile V, Benatti P, Ferrari E, Marverti G and Imbriano C. Concurrent inhibition of enzymatic activity and NF-Y-mediated transcription of Topoisomerase-IIalpha by bis-DemethoxyCurcumin in cancer cells. Cell Death Dis. 2013; 4:e756.

9. Fryer RA, Barlett B, Galustian $\mathrm{C}$ and Dalgleish AG. Mechanisms underlying gemcitabine resistance in pancreatic cancer and sensitisation by the iMiD lenalidomide. Anticancer Res. 2011; 31:3747-3756.

10. Vurusaner B, Poli G and Basaga H. Tumor suppressor genes and ROS: complex networks of interactions. Free Radic Biol Med. 2012; 52:7-18.

11. Sahoo K, Dozmorov MG, Anant S and Awasthi V. The curcuminoid CLEFMA selectively induces cell death in H441 lung adenocarcinoma cells via oxidative stress. Invest New Drugs. 2012; 30:558-567.

12. Halliwell B. The wanderings of a free radical. Free Radic Biol Med. 2009; 46:531-542.

13. Rao J, Xu DR, Zheng FM, Long ZJ, Huang SS, Wu X, Zhou WH, Huang RW and Liu Q. Curcumin reduces expression of $\mathrm{Bcl}-2$, leading to apoptosis in daunorubicin-insensitive CD34+ acute myeloid leukemia cell lines and primary sorted CD34+ acute myeloid leukemia cells. J Transl Med. 2011; 9:71.

14. Yang PM, Lin YT, Shun CT, Lin SH, Wei TT, Chuang SH, $\mathrm{Wu}$ MS and Chen CC. Zebularine inhibits tumorigenesis and stemness of colorectal cancer via p53-dependent endoplasmic reticulum stress. Sci Rep. 2013; 3:3219.

15. Shore GC, Papa FR and Oakes SA. Signaling cell death from the endoplasmic reticulum stress response. Curr Opin Cell Biol. 2011; 23:143-149.

16. Patel N, Chatterjee SK, Vrbanac V, Chung I, Mu CJ, Olsen RR, Waghorne $\mathrm{C}$ and Zetter BR. Rescue of paclitaxel sensitivity by repression of Prohibitin1 in drugresistant cancer cells. Proc Natl Acad Sci U S A. 2010; 107:2503-2508.

17. Chen Y, Kang M, Lu W, Guo Q, Zhang B, Xie Q and Wu Y. DJ-1, a novel biomarker and a selected target gene for overcoming chemoresistance in pancreatic cancer. J Cancer Res Clin Oncol. 2012; 138:1463-1474.

18. Thuaud F, Ribeiro N, Nebigil CG and Desaubry L. Prohibitin ligands in cell death and survival: mode of action and therapeutic potential. Chem Biol. 2013; 20:316-331.

19. Mencalha A, Victorino VJ, Cecchini R and Panis C. Mapping oxidative changes in breast cancer: understanding the basic to reach the clinics. Anticancer Res. 2014; 34:1127-1140.
20. Griffiths HR, Dias IH, Willetts RS and Devitt A. Redox regulation of protein damage in plasma. Redox Biol. 2014; 2:430-435.

21. Wu YT, Wu SB and Wei YH. Metabolic Reprogramming of Human Cells in Response to Oxidative Stress: Implications in the Pathophysiology and Therapy of Mitochondrial Diseases. Curr Pharm Des. 2014.

22. Rajasekaran SA. Therapeutic potential of curcumin in gastrointestinal diseases. World J Gastrointest Pathophysiol. 2011; 2:1-14.

23. Gupta SC, Patchva S, Koh W and Aggarwal BB. Discovery of curcumin, a component of golden spice, and its miraculous biological activities. Clin Exp Pharmacol Physiol. 2012; 39:283-299.

24. Gopal PK, Paul M and Paul S. Curcumin Induces Caspase Mediated Apoptosis in JURKAT Cells by Disrupting the Redox Balance. Asian Pacific journal of cancer prevention. 2014; 15:93-100.

25. Redza-Dutordoir M and Averill-Bates DA. Activation of apoptosis signalling pathways by reactive oxygen species. Biochim Biophys Acta. 2016; 1863:2977-2992.

26. Valko M, Leibfritz D, Moncol J, Cronin MT, Mazur M and Telser J. Free radicals and antioxidants in normal physiological functions and human disease. Int J Biochem Cell Biol. 2007; 39:44-84.

27. Szegezdi E, Logue SE, Gorman AM and Samali A. Mediators of endoplasmic reticulum stress-induced apoptosis. EMBO Rep. 2006; 7:880-885.

28. Firczuk M, Gabrysiak M, Barankiewicz J, Domagala A, Nowis D, Kujawa M, Jankowska-Steifer E, Wachowska M, Glodkowska-Mrowka E, Korsak B, Winiarska M and Golab J. GRP78-targeting subtilase cytotoxin sensitizes cancer cells to photodynamic therapy. Cell Death Dis. 2013; 4:e741.

29. Seervi M, Sobhan PK, Joseph J, Ann Mathew K and Santhoshkumar TR. ERO1alpha-dependent endoplasmic reticulum-mitochondrial calcium flux contributes to ER stress and mitochondrial permeabilization by procaspaseactivating compound-1 (PAC-1). Cell Death Dis. 2013; 4:e968.

30. Tabas I and Ron D. Integrating the mechanisms of apoptosis induced by endoplasmic reticulum stress. Nat Cell Biol. 2011; 13:184-190.

31. Matsumoto H, Miyazaki S, Matsuyama S, Takeda M, Kawano M, Nakagawa H, Nishimura K and Matsuo S. Selection of autophagy or apoptosis in cells exposed to ER-stress depends on ATF4 expression pattern with or without CHOP expression. Biol Open. 2013; 2:1084-1090.

32. Brem GJ, Mylonas I and Bruning A. Eeyarestatin causes cervical cancer cell sensitization to bortezomib treatment by augmenting ER stress and CHOP expression. Gynecol Oncol. 2013; 128:383-390.

33. Suk FM, Lien GS, Huang WJ, Chen CN, Lu SY, Yang YC, Yan MD and Liang YC. A Taiwanese Propolis Derivative 
Induces Apoptosis through Inducing Endoplasmic Reticular Stress and Activating Transcription Factor-3 in Human Hepatoma Cells. Evid Based Complement Alternat Med. 2013; 2013:658370.

34. Cruickshanks N, Tang Y, Booth L, Hamed H, Grant S and Dent P. Lapatinib and obatoclax kill breast cancer cells through reactive oxygen species-dependent endoplasmic reticulum stress. Mol Pharmacol. 2012; 82:1217-1229.

35. Anderica-Romero AC, Gonzalez-Herrera IG, Santamaria A and Pedraza-Chaverri J. Cullin 3 as a novel target in diverse pathologies. Redox Biol. 2013; 1:366-372.

36. Zhao Y and Sun Y. Cullin-RING Ligases as attractive anticancer targets. Curr Pharm Des. 2013; 19:3215-3225.

37. Nawrocki ST, Kelly KR, Smith PG, Espitia CM, Possemato A, Beausoleil SA, Milhollen M, Blakemore S, Thomas M, Berger A and Carew JS. Disrupting protein NEDDylation with MLN4924 is a novel strategy to target cisplatin resistance in ovarian cancer. Clin Cancer Res. 2013; 19:3577-3590.

38. Haagenson KK, Tait L, Wang J, Shekhar MP, Polin L, Chen $\mathrm{W}$ and $\mathrm{Wu}$ GS. Cullin-3 protein expression levels correlate with breast cancer progression. Cancer Biol Ther. 2012; 13:1042-1046.

39. Jia JW, Li KL, Wu JX and Guo SL. Clinical significance of annexin II expression in human non-small cell lung cancer. Tumour Biol. 2013; 34:1767-1771.

40. Zhai H, Acharya S, Gravanis I, Mehmood S, Seidman RJ, Shroyer KR, Hajjar KA and Tsirka SE. Annexin A2 promotes glioma cell invasion and tumor progression. J Neurosci. 2011; 31:14346-14360.

41. Ranjan AP, Mukerjee A, Helson L, Gupta R and Vishwanatha JK. Efficacy of liposomal curcumin in a human pancreatic tumor xenograft model: inhibition of tumor growth and angiogenesis. Anticancer Res. 2013; 33:3603-3609.

42. An Y, Zhang JZ, Han J, Yang HP, Tie L, Yang XY, Xiaokaiti Y, Pan Y and Li XJ. Hypoxia-inducible factor-1alpha dependent pathways mediate the renoprotective role of acetazolamide against renal ischemia-reperfusion injury. Cell Physiol Biochem. 2013; 32:1151-1166.
43. Pan Y, Li X, Duan J, Yuan L, Fan S, Fan J, Xiaokaiti Y, Yang H, Wang Y and Li X. Enoxaparin sensitizes human non-small-cell lung carcinomas to gefitinib by inhibiting DOCK1 expression, vimentin phosphorylation, and Akt activation. Mol Pharmacol. 2015; 87:378-390.

44. Keshava Prasad TS, Goel R, Kandasamy K, Keerthikumar S, Kumar S, Mathivanan S, Telikicherla D, Raju R, Shafreen B, Venugopal A, Balakrishnan L, Marimuthu A, Banerjee S, Somanathan DS, Sebastian A, Rani S, et al. Human Protein Reference Database--2009 update. Nucleic Acids Res. 2009; 37:D767-772.

45. Zanzoni A, Montecchi-Palazzi L, Quondam M, Ausiello G, Helmer-Citterich M and Cesareni G. MINT: a Molecular INTeraction database. FEBS Lett. 2002; 513:135-140.

46. Aranda B, Achuthan P, Alam-Faruque Y, Armean I, Bridge A, Derow C, Feuermann M, Ghanbarian AT, Kerrien S, Khadake J, Kerssemakers J, Leroy C, Menden M, Michaut M, Montecchi-Palazzi L, Neuhauser SN, et al. The IntAct molecular interaction database in 2010. Nucleic Acids Res. 2010; 38:D525-531.

47. Salwinski L, Miller CS, Smith AJ, Pettit FK, Bowie JU and Eisenberg D. The Database of Interacting Proteins: 2004 update. Nucleic Acids Res. 2004; 32:D449-451.

48. Breitkreutz BJ, Stark C, Reguly T, Boucher L, Breitkreutz A, Livstone M, Oughtred R, Lackner DH, Bahler J, Wood V, Dolinski K and Tyers M. The BioGRID Interaction Database: 2008 update. Nucleic Acids Res. 2008; 36:D637-640.

49. Pagel P, Kovac S, Oesterheld M, Brauner B, DungerKaltenbach I, Frishman G, Montrone C, Mark P, Stumpflen V, Mewes HW, Ruepp A and Frishman D. The MIPS mammalian protein-protein interaction database. Bioinformatics. 2005; 21:832-834.

50. Fan S, Geng Q, Pan Z, Li X, Tie L, Pan Y and Li X. Clarifying off-target effects for torcetrapib using network pharmacology and reverse docking approach. BMC Syst Biol. 2012; 6:152.

51. Xiaokaiti Y, Wu H, Chen Y, Yang H, Duan J, Li X, Pan Y, Tie L, Zhang L and Li X. EGCG reverses human neutrophil elastase-induced migration in A549 cells by directly binding to HNE and by regulating alpha1-AT. Sci Rep. 2015; 5:11494. 